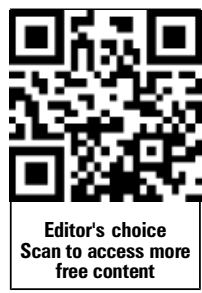

'Department of Community Dentistry, School of Dentistry, Oregon Health and Science University, Portland, Oregon, USA

${ }^{2}$ Faculty of Health and Medical Sciences, Institute of Public Health Science, University of Copenhagen, Copenhagen, Denmark

${ }^{3}$ Department of Epidemiology and Public Health, University College London, London, UK

Correspondence to Dr Wael Sabbah, Department of Community Dentistry, School of Dentistry, Oregon Health and Science University, 611 S.W. Campus Drive, Portland, OR 97239-3097, USA:

sabbah@ohsu.edu

Accepted 13 August 2012 Published Online First 25 September 2012

\section{SLinked}

http://dx.doi.org/10.1136/ jech-2013-202481

To cite: Sabbah W, Mortensen LH, Sheiham A et al. J Epidemiol Community Health 2013;67:392-397.

\title{
Oral health as a risk factor for mortality in middle-aged men: the role of socioeconomic position and health behaviours
}

\author{
Wael Sabbah, ${ }^{1}$ Laust Hvas Mortensen, ${ }^{2}$ Aubrey Sheiham, ${ }^{3}$ David Batty ${ }^{3}$
}

\begin{abstract}
Background There is evidence of an association between poor oral health and mortality. This association is usually attributed to inflammatory and nutrition pathways. However, the role of health behaviours and socioeconomic position has not been adequately examined. The aims of this study were to examine the association between oral health and premature death among middle-aged men and to test whether it was explained by socioeconomic position and behaviours. Methods Data were from the Vietnam Experience Study, a prospective cohort study of Vietnam War-era (1965-1971), American male army personnel. The authors examined risk of cause-specific and all-cause mortality in relation to poor oral health in middle age, adjusting for age, ethnicity, socioeconomic position, IQ,
\end{abstract} behavioural factors and systemic conditions.

Results Men with poor oral health experienced a higher risk of cause-specific and all-cause mortality. HRs for all-cause mortality were 2.94 ( $95 \% \mathrm{Cl} 2.11$ to 4.08 ) among individuals with poor oral health and 3.98 (95\% CI 2.43 to 6.49) among edentates compared with those with good oral health after adjusting for ethnicity and age. The association attenuated but remained significant after further adjustment for systemic conditions, socioeconomic position and behaviours. Socioeconomic and behavioural factors explained $52 \%$ and $44 \%$ of mortality risks attributed to poor oral health and being edentate, respectively.

Conclusion The findings suggest that oral healthmortality relation is partly due to measured covariates in the present study. Oral health appears to be a marker of socioeconomic and behavioural risk factors related to allcause mortality.

\section{INTRODUCTION}

There is mounting evidence for an association between poorer oral health, particularly periodontal disease and number of teeth, and risk of causespecific and all-cause mortality. ${ }^{1-15}$ Various explanations for these relationships have been advanced. Investigators have postulated that an inflammatory pathway may link periodontal disease with cardiovascular disease and respiratory-related mortality. ${ }^{41016}$ Others have argued that tooth loss affects the ability to eat and consequently impacts on the intake of key nutrients ${ }^{17}$ that have been linked to cardiovascular disease and cancer mortality. ${ }^{2} 18$

All-cause mortality is linked to a cluster of health-compromising behaviours, ${ }^{19-21}$ which are also related to oral health. ${ }^{22}$ It is therefore plausible that oral health status is an early marker of lifestyle, risk taking and health-compromising behaviours linked to all-cause mortality. Furthermore, cognitive ability and intelligence are also associated with both mortality ${ }^{23}$ and oral health ${ }^{24}$ and could also be implicated in the association between oral health and all-cause mortality. Finally, socioeconomic position, a common determinant of oral health and mortality, may plausibly explain some of the relationship between oral health and mortality. ${ }^{25}$

While the relationship between oral health and all-cause mortality has been frequently documented, no study has examined whether all or part of this association could be explained by the common association between each of oral health and allcause mortality on the one hand, and socioeconomic position and health-related behaviours on the other. Accordingly, the present study has two objectives: (1) to examine the relationship between oral health in middle age and causespecific and all-cause mortality and (2) to assess what portion of this association, if any, could be explained by socioeconomic position, intelligence and selected health-compromising behaviours.

\section{METHODS}

\section{Study population}

Data were from the Vietnam Experience Study, a prospective cohort study of Vietnam War-era military veterans who had entered the US military service between January 1965 and December 1971. A detailed description of the survey and the sampling frame are described elsewhere. ${ }^{26-32}$ In brief, participants were veterans who served in Vietnam, Korea, Germany and the USA. ${ }^{31}$ In 1984 , a subsample of living veterans participated in telephone interview $(\mathrm{n}=15288)$. A random sample of those who participated in the interview was invited for medical examination $(n=6443)$, with 4462 participating. ${ }^{26}{ }^{31}$ An additional 274 individuals were excluded for having missing data on any of the variables in the analytical sample. All participants were men, with an average age of 20 years (range $16-33$ years) at induction into the military.

\section{Assessment of oral health}

During the physical examination, physicians performed a qualitative assessment of the throat, mouth, teeth, gums and tongue of the study members. The presence of ulcers, masses, gingival condition, plaque, being edentate and use of dentures were noted. Dental status was reported as good, fair, poor or edentulous. 'Good' oral health status was denoted by an absence of caries and gingivitis; 'fair' oral health was indicated by some abnormalities of teeth and gum; 'poor' oral health 
included the presence of severe gingival and dental disease; edentulous is self-explanatory. ${ }^{26}$ This variable was used to assess mortality risk in relation to the deterioration of oral health. Earlier studies have suggested that physicians can accurately assess the oral health of adults ${ }^{33-35}$ and children. ${ }^{36} 37$ Furthermore, considering the fact that oral health was assessed at a relatively young age, and the significance of being completely edentulous as more objective indicator of poor dental status, two dichotomous indicators of oral health were created: (1) good versus poor (fair, poor, edentulous) and (2) edentulous versus dentate. These two variables were used in assessing risk of all-cause mortality and estimating the impact of socioeconomic and behavioural factors on the association between oral health and all-cause mortality.

\section{Ascertainment of mortality}

Vital status postmedical examination was tracked until 31 December 2000; cause of mortality was ascertained from death certificate. The majority of deaths were ascribed to neoplasm (20.8\%) (ICD-9: 140-239; ICD-10: C00-D48), diseases of heart (23.2\%) (ICD-9: 390-398, 402, 404, 410-429; ICD-10: I00-I09, I11, I13, I20-I) and external causes (22\%) (ICD-9: E800-E999; ICD-10: V01-Y89). ${ }^{38}$

\section{Covariate data}

Pay grade at discharge from the army (five categories), years of education $(<12,12$ and $>12$ years $)$ and midlife family income $(\leq \$ 20000, \$ 20001-30000,>\$ 30000)$ were used as indicators of socioeconomic position. The validated Army General Technical Test, which provides measure of IQ, was administered on entering the service. Health-related behaviours included the following variables, collected at midlife: number of years the participant smoked, alcohol units consumed per day, whether the study member had counselling or treatment for drug or alcohol abuse and body mass index (BMI) (as a marker of diet and physical activity). BMI was categorised into four groups: $<18.5,18.5$ to $<25,25$ to $<30$ and 30 US units or more. Ethnicity (white, black and other ethnicities including Hispanics) and age in days at examination in 1984 were also used as covariates in the analysis. To adjust for general medical conditions and biological risk factors for cardiovascular disease at time of physical examination, the following variables were added to the multivariable model: total cholesterol, High-density lipoprotein (HDL)-Cholesterol diagnosis of hypertension, heart murmur, angina, heart attack, heart failure, endocarditis, pericarditis, and diabetes.

\section{Data analysis}

The characteristics of study members according to the oral health status (good, fair, poor or edentulous) were examined. Participants were considered to be at risk of dying between the completion of the 1984 evaluation until death or the end of December 2000, whichever came first. Having determined that the proportional hazard assumption had not been violated, the associations of oral health with all-cause and cause-specific mortality, namely neoplasm, disease of the heart and external causes of death, were assessed. Two Cox regression models were constructed for each cause of mortality, the first adjusting for age at examination and ethnicity and the second additionally adjusting for all other covariates (socioeconomic, behavioural and medical conditions).

The associations between all-cause mortality and socioeconomic position (education, military pay grade, family income and standardised IQ score), and behaviours (smoking, alcohol consumption, treatment/counselling for alcohol or drugs abuse and BMI) were assessed, adjusting for ethnicity and age at examination.

Using the two dichotomous variables (poor vs good oral health) and (edentulous vs dentate), two sets of Cox models were used to assess changes in the HRs for all-cause mortality after adjusting for (1) chronic conditions, (2) socioeconomic and (3) behavioural factors. The build-up of the models was designed to allow quantifying the specific impacts of socioeconomic, behavioural and chronic conditions at midlife on the relationship between oral health and all-cause mortality. Model 1 was adjusted for one of the oral health dichotomous variables, ethnicity and age at the time of examination. Model 2 additionally included total cholesterol, HDL-cholesterol, cardiac conditions, diabetes and hypertension. Model 3 included socioeconomic position (pay grade at discharge from army, family income at midlife, years of education and IQ) in addition to the variables in model 1 . Model 4 included behavioural variables at midlife (smoking, alcohol, counselling/treatment for drug or alcohol abuse and BMI) in addition to the variables in model 1. Model 5 included all the variables in models 3 and 4 (socioeconomic and behavioural factors). Finally, model 6 was adjusted for all the variables included in the previous models. To quantify the contribution of socioeconomic, behavioural variables and medical conditions to the association between oral health and all-cause mortality, the following formula was used:

$$
\begin{aligned}
& \text { Percentage Reduction in Hazard }= \\
& \left(\text { Hazard }_{\text {dental }}\right. \text { status (Model 1)- } \\
& \text { Hazard }_{\text {dental }} \text { status (Model 2))/ } \\
& \left.\left(\text { Hazard }_{\text {dental }} \text { status (Model } 1\right)-1\right)
\end{aligned}
$$

The formula was applied to models 3-6. This method was used in previous studies and can, despite some methodological shortcomings, ${ }^{39}$ be used as a heuristic to get a rough estimate of the contribution of socioeconomic position to variation in health. ${ }^{40}$ Finally, a sensitivity analysis was conducted excluding those who died in the first 7 years to account for any undiagnosed disease at study entry (reverse causality). The use of a 7-year period was inevitably arbitrary and has been used in earlier study. ${ }^{29}$

\section{RESULTS}

Of the 4462 participants who had the physical examination at midlife, 4188 participants with complete data for all variables were included in this analysis. ${ }^{32}$ There was no difference in mortality rates or in oral health between those excluded from the analysis and the original sample. Overall, 63.3\%, 23.0\%, 10.6\% and $3.1 \%$ were assessed as having good, fair, poor oral health and edentulous, respectively. The number of deaths from any cause was 234. The number of deaths from neoplasm, cardiovascular disease and external causes were 48, 62 and 49, respectively. The mean age at time of physical examination and at the end of mortality follow-up was 38.3 and 53.0 years, respectively. The average follow-up period was 30.4 years. Table 1 shows the distribution of all variables included in the analysis for the whole sample and by oral health status.

The assessment of cause-specific and all-cause mortality hazard by oral health revealed that edentulous veterans HRs of 3.06 (95\% CI 1.06 to 8.77), 5.47 (95\% CI 2.38 to 12.60 ), 3.88 (95\% CI 1.34 to 11.29 ) and 3.98 (95\% CI 2.43 to 6.49 ) for mortality related to neoplasm, cardiovascular diseases, external causes and all-cause, respectively. However, the association 
Table 1 Characteristics of study members inducted in military service between 1965 and 1971, by oral health status $(N=4188)$

\begin{tabular}{|c|c|c|c|c|c|}
\hline \multirow[b]{2}{*}{ Variables } & \multicolumn{4}{|c|}{ Within groups of oral health status } & \multirow{2}{*}{$\begin{array}{l}\text { Within the whole } \\
\text { population }\end{array}$} \\
\hline & Good & Fair & Poor & Edentulous & \\
\hline \multicolumn{6}{|l|}{ Mortality rates } \\
\hline All-cause mortality (\%) & 4.0 & 5.5 & 12.4 & 14.5 & 5.6 \\
\hline Neoplasm mortality & 1.0 & 1.0 & 1.8 & 3.1 & 1.1 \\
\hline Coronary heart disease mortality & 1.1 & 1.0 & 3.6 & 5.3 & 1.5 \\
\hline External cause mortality & 0.9 & 1.4 & 2.0 & 3.1 & 1.2 \\
\hline \multicolumn{6}{|l|}{ Covariates } \\
\hline Mean age at examination $(95 \% \mathrm{Cl})$ & 38.4 (38.3 to 38.4$)$ & 38.3 (38.1 to 38.4$)$ & $38.3(38.0$ to 38.5$)$ & 38.8 (38.4 to 39.2$)$ & $38.3(38.3$ to 38.4$)$ \\
\hline \multicolumn{6}{|l|}{ Ethnicity (\%) } \\
\hline White & 85.2 & 82.1 & 73.2 & 90.8 & 83.4 \\
\hline Black & 10.0 & 12.8 & 23.2 & 9.2 & 12.0 \\
\hline Hispanic/others & 4.8 & 5.2 & 3.6 & 0.0 & 4.6 \\
\hline \multicolumn{6}{|l|}{ Education (\%) } \\
\hline$<12$ years & 8.8 & 12.9 & 25.5 & 26.7 & 12.1 \\
\hline$=12$ years & 33.7 & 40.5 & 42.8 & 52.7 & 36.8 \\
\hline$>12$ years & 57.5 & 46.7 & 31.8 & 20.6 & 51.2 \\
\hline \multicolumn{6}{|l|}{ Pay grade at discharge from army (\%) } \\
\hline Lowest & 2.1 & 2.7 & 9.0 & 6.9 & 3.1 \\
\hline 2nd lowest & 2.8 & 3.5 & 3.2 & 3.8 & 3.1 \\
\hline Middle & 5.2 & 7.5 & 7.7 & 9.2 & 6.1 \\
\hline 2nd highest & 48.0 & 51.4 & 54.1 & 52.7 & 49.6 \\
\hline Highest & 42.0 & 35.0 & 25.7 & 27.5 & 38.2 \\
\hline \multicolumn{6}{|l|}{ Family income at midlife (\%) } \\
\hline$>\$ 30000$ & 50.2 & 41.2 & 19.1 & 24.4 & 44.0 \\
\hline$>\$ 20000$ to $\leq \$ 30000$ & 27.3 & 28.1 & 28.2 & 34.4 & 27.8 \\
\hline$\leq \$ 20000$ & 22.5 & 30.7 & 52.7 & 41.2 & 28.2 \\
\hline Mean IQ in early adulthood $(95 \% \mathrm{Cl})$ & $109.3(108.5$ to 110.0$)$ & $104.0(102.7$ to 105.3$)$ & 96.1 (94.3 to 97.8$)$ & 96.0 (92.8 to 99.1$)$ & 106.2 (105.6 to 106.8$)$ \\
\hline Mean number of years smoked $(95 \% \mathrm{Cl})$ & $7.0(6.6$ to 7.3$)$ & $9.7(9.1$ to 10.3$)$ & $12.8(11.9$ to 13.7$)$ & $14.2(12.4$ to 16.0$)$ & $8.5(8.1$ to 8.7$)$ \\
\hline Mean number of alcohol units per day $(95 \% \mathrm{Cl})$ & $2.7(2.5$ to 2.8$)$ & $3.1(2.9$ to 3.3$)$ & 3.7 (3.3 to 4.1$)$ & $2.9(2.3$ to 3.4$)$ & $2.9(2.8$ to 3.0$)$ \\
\hline $\begin{array}{l}\text { Had treatment or counselling for alcohol } \\
\text { or drug abuse }(\%)\end{array}$ & 8.8 & 10.9 & 15.8 & 13.7 & 10.2 \\
\hline Mean body mass index at midlife $(95 \% \mathrm{Cl})$ & $26.8(6.5$ to 27.1$)$ & $28.5(28.0$ to 29.0$)$ & $27.3(27.1$ to 27.6$)$ & $30.5(28.7$ to 32.4$)$ & 27.4 (27.2 to 27.7$)$ \\
\hline Mean cholesterol $(95 \% \mathrm{CI})$ & 5.5 (5.4 to 5.5$)$ & 5.5 (5.4 to 5.6$)$ & 5.5 (5.4 to 5.6$)$ & $5.7(5.5$ to 5.9$)$ & $5.5(5.4$ to 5.5$)$ \\
\hline Mean HDL-cholesterol $(95 \% \mathrm{Cl})$ & $1.2(1.1$ to 1.2$)$ & $1.1(1.1$ to 1.2$)$ & $1.2(1.1$ to 1.2$)$ & $1.1(1.1$ to 1.2$)$ & $1.2(1.1$ to 1.2$)$ \\
\hline Hypertensive (\%) & 9.5 & 10.6 & 13.5 & 7.7 & 10.1 \\
\hline Heart murmur (\%) & 8.3 & 7.7 & 8.8 & 9.9 & 8.3 \\
\hline Angina (\%) & 0.6 & 0.5 & 1.6 & 00 & 0.7 \\
\hline Heart attack (\%) & 0.5 & 0.5 & 0.7 & 00 & 0.5 \\
\hline Heart failure (\%) & 0.1 & 0.1 & 0.2 & 00 & 0.1 \\
\hline Endocarditis (\%) & 0.1 & 0.0 & 0.0 & 0.8 & 0.1 \\
\hline Pericarditis (\%) & 0.3 & 0.6 & 0.2 & 00 & 0.4 \\
\hline Diabetes (\%) & 0.9 & 0.8 & 1.6 & 1.5 & 1.0 \\
\hline
\end{tabular}

between being edentulous and mortality related to neoplasm and external causes lost significance after adjusting for socioeconomic, behavioural factors and chronic conditions. Persons assessed as having 'poor' oral health were at significantly higher risk of cardiovascular disease and all-cause mortality than those assessed as having 'good' oral health. On the other hand, there was no significant difference in mortality risk between those assessed as having 'fair' and 'good' oral health (table 2).

In the sensitivity analysis excluding those who died in the first 7 years after study entry, the association between all-cause mortality and oral health was consistent with that obtained from the analysis of the whole sample. In the sensitivity analysis, veterans assessed as having 'fair', 'poor' oral health or edentulous had HRs of 1.26 (95\% CI 0.84 to 1.90 ), 1.80 (95\% CI 1.15 to 2.82 ) and 3.73 (95\% CI 2.05 to 6.76), respectively, for all-cause mortality.
Table 3 exhibits the HRs for all-cause mortality by socioeconomic and behavioural covariates, adjusting for ethnicity and age at examination. There were clear socioeconomic gradients in the risk of all-cause mortality using indicators from early adulthood and midlife. The standardised score of IQ as measured in early adulthood was significantly related to mortality with individuals with a SD higher than the average IQ having lower hazard of mortality of 0.35 (95\% CI 0.18 to 0.66 ). Years of smoking, units of alcohol and treatment or counselling for alcohol or drugs abuse were all related to the risk of total mortality (table 2).

Table 4 exhibits the impact of adjusting for socioeconomic and behavioural factors on the association between oral health and all-causes mortality. Men with poor oral health had a HR of 2.02 (95\% CI 1.56 to 2.64) for all-cause mortality; after adjusting for chronic conditions, this association attenuated to 2.01 
Table 2 HR $(95 \% \mathrm{Cl})$ for cause-specific and all-cause mortality in relation to oral health status (four groups), among veterans inducted in military service between 1965 and $1971(\mathrm{~N}=4188)$

\begin{tabular}{|c|c|c|c|c|}
\hline & \multicolumn{4}{|c|}{ HRs for mortality $(95 \% \mathrm{Cl})$ by oral health status } \\
\hline & Good (ref) & Fair & Poor & Edentulous \\
\hline \multicolumn{5}{|c|}{ Neoplasm mortality } \\
\hline Model 1 & 1 & $1.08^{\mathrm{NS}}(0.52$ to 2.24$)$ & $1.90^{\mathrm{NS}}(0.86$ to 4.24$)$ & $3.06^{*}(1.06$ to 8.77$)$ \\
\hline Model 2 & 1 & $1.00^{\mathrm{NS}}(0.47$ to 2.10$)$ & $1.65^{\mathrm{NS}}(0.70$ to 3.88$)$ & $1.88^{\mathrm{NS}}(0.54$ to 6.59$)$ \\
\hline \multicolumn{5}{|c|}{ Cardiovascular mortality } \\
\hline Model 1 & 1 & $0.94^{\mathrm{NS}}(0.46$ to 1.94$)$ & $3.34^{* * *}(1.80$ to 6.20$)$ & $5.47^{* * *}(2.38$ to 12.60$)$ \\
\hline Model 2 & 1 & $0.74^{\mathrm{NS}}(0.35$ to 1.57$)$ & $2.16^{*}(1.09$ to 4.26$)$ & $4.72^{* *}(1.93$ to 11.53$)$ \\
\hline \multicolumn{5}{|c|}{ External causes of mortality } \\
\hline Model 1 & 1 & $1.61^{\mathrm{NS}}(0.81$ to 3.20$)$ & $2.44 *(1.12$ to 5.32$)$ & $3.88^{*}(1.34$ to 11.29$)$ \\
\hline Model 2 & 1 & $1.36^{\mathrm{NS}}(0.68$ to 2.74$)$ & $1.65^{\mathrm{NS}}(0.72$ to 3.81$)$ & $2.49^{\mathrm{NS}}(0.82$ to 7.62$)$ \\
\hline \multicolumn{5}{|c|}{ All-cause mortality } \\
\hline Model 1 & 1 & $1.35^{\mathrm{NS}} \pm(0.97$ to 1.88$)$ & $2.94^{* * *}(2.11$ to 4.08$)$ & $3.98^{* * *}(2.43$ to 6.49$)$ \\
\hline Model 2 & 1 & $1.13^{\mathrm{NS}}(0.81$ to 1.58$)$ & $1.87^{* *}(1.31$ to 2.66$)$ & $2.71^{* * *}(1.60$ to 4.59$)$ \\
\hline
\end{tabular}

(95\% CI 1.55 to 2.61), explaining essentially none of the relationship. After adjusting for socioeconomic and behavioural factors, but not for chronic conditions, the HR was attenuated to 1.49 (95\% CI 1.14 to 1.95 ). Socioeconomic and behavioural factors explained $33.3 \%$, and $36.3 \%$ of all-cause mortality hazard attributed to poor oral health, respectively (table 4). Being edentulous showed a HR of 3.01 (95\% CI 1.91 to 4.91) in the initial model adjusting for age and ethnicity. After adding

Table 3 HR $(95 \% \mathrm{Cl})$ for the relation of covariates with total mortality among veterans inducted in military service between 1965 and $1971(\mathrm{~N}=4188)$

\begin{tabular}{|c|c|}
\hline & HR $(95 \% \mathrm{Cl})$ \\
\hline \multicolumn{2}{|l|}{ Ethnicity } \\
\hline White & 1 (ref) \\
\hline Black & $2.35^{* *}(1.73$ to 3.20$)$ \\
\hline Other ethnicities & $2.07^{* * *}(1.27$ to 3.37$)$ \\
\hline \multicolumn{2}{|l|}{ Education (years) } \\
\hline$>12$ & 1 (ref) \\
\hline$=12$ & $1.85^{* * *}(1.39$ to 2.46$)$ \\
\hline$<12$ & $2.23^{* * *}(1.54$ to 3.22$)$ \\
\hline \multicolumn{2}{|l|}{ Pay grade at discharge from army } \\
\hline Highest & 1 (ref) \\
\hline 2nd highest & $1.53^{* *}(1.13$ to 2.06$)$ \\
\hline Middle & $1.90^{*}(1.14$ to 3.16$)$ \\
\hline 2nd lowest & $1.91^{\mathrm{NS}}(0.99$ to 3.66$)$ \\
\hline Lowest & $2.31^{*}(1.21$ to 4.39$)$ \\
\hline \multicolumn{2}{|l|}{ Family income at midlife } \\
\hline$>\$ 30000$ & 1 (ref) \\
\hline$>\$ 20000$ to $\leq \$ 30000$ & $1.94^{* * *}(1.37$ to 2.75$)$ \\
\hline$\leq \$ 20000$ & $2.82^{* * *}(2.03$ to 3.92$)$ \\
\hline Standardised IQ score at early adulthood & $0.35^{* *}(0.18$ to 0.66$)$ \\
\hline Mean number of years smoked & $1.05^{* * *}(1.03$ to 1.06$)$ \\
\hline Mean number of alcohol units per day & $1.08^{* * *}(1.05$ to 1.10$)$ \\
\hline Had treatment or counselling for alcohol or drug abuse & $3.62^{* * *}(2.71$ to 4.84$)$ \\
\hline Body mass index at midlife & $1.01^{\mathrm{NS}}(0.99$ to 1.03$)$ \\
\hline
\end{tabular}

socioeconomic factors to the multivariable model, the effect estimate was attenuated to 2.26 (95\% CI 1.40 to 3.66), explaining $37.3 \%$ of the risk attributed to being edentulous. In the model adjusting only for behavioural factors, the hazard risks (HRs) were 2.49 (95\% CI 1.54 to 4.03 ) with $25.9 \%$ reduction in the risk attributed to being edentulous. When behavioural and socioeconomic factors were included in the same model, but not chronic conditions, $44.3 \%$ of the association between being edentulous and mortality was explained. In the fully adjusted model, the HR attenuated to 2.15 (95\% CI 1.30 to 3.55 ) and remained significant (table 4).

\section{DISCUSSION}

Data from the Vietnam Experience Study were used to examine the association between physician-assessed oral health status and all-cause mortality at middle age and to ascertain whether this relationship could be explained by socioeconomic and behavioural factors. Veterans assessed as having poor oral health and being edentulous were significantly associated with increased allcause mortality and cardiovascular mortality. The association between oral health, and cardiovascular and all-cause mortality attenuated but was not eliminated after adjusting for chronic conditions at midlife, socioeconomic position and behavioural factors. Poorer oral health and being edentulous were also associated with the risk of mortality from external causes. However, this association disappeared after adjusting for behavioural and socioeconomic factors.

Socioeconomic position and some selected healthcompromising behaviours explained roughly $50 \%$ of the association between oral health and all-cause mortality. On the other hand, chronic health conditions and biological risk factors for cardiovascular disease had little or no impact on the association between oral health and all-cause mortality.

The relationship between oral health and all-cause mortality among the US veterans demonstrated in this study is consistent with findings from elsewhere. ${ }^{2} 367$ 12-15 Many of the aforementioned studies attributed the association between oral health and mortality to the dissemination of inflammation resulting from oral infection. ${ }^{4} 10 \quad 16$ Others suggested that tooth loss could be a risk for mortality through an effect on eating ability and nutrients intake. ${ }^{2} 718$ While these pathways undoubtedly 
Table 4 HR $(95 \% \mathrm{Cl})$ for all-cause mortality in relation to oral health status among veterans inducted in military service between 1965 and 1971 ( $\mathrm{N}=4188)$

\begin{tabular}{|c|c|c|}
\hline & HR (95\% Cl) & $\begin{array}{l}\text { Percentage } \\
\text { reduction } \\
\text { in HR }\end{array}$ \\
\hline \multicolumn{3}{|l|}{ Oral health (poor) } \\
\hline $\begin{array}{l}\text { Model 1: adjusted for age and } \\
\text { ethnicity }\end{array}$ & $2.02^{* * *}$ (1.56 to 2.62$)$ & \\
\hline $\begin{array}{l}\text { Model 2: systemic conditions + } \\
\text { model } 1\end{array}$ & $2.01^{* * *}(1.55$ to 2.61$)$ & 1.0 \\
\hline $\begin{array}{l}\text { Model 3: socioeconomic factors + } \\
\text { model } 1\end{array}$ & $1.68^{* * *}(1.29$ to 2.20$)$ & 33.3 \\
\hline $\begin{array}{l}\text { Model 4: behavioural factors + } \\
\text { model } 1\end{array}$ & $1.65^{* * *}(1.26$ to 2.15$)$ & 36.3 \\
\hline Model 5: models 3+4 & $1.49 * *(1.14$ to 1.95$)$ & 52.0 \\
\hline Model 6: models $2+3+4$ & $1.46^{* *}(1.12$ to 1.92$)$ & 54.9 \\
\hline \multicolumn{3}{|l|}{ Dental status (edentulous) } \\
\hline $\begin{array}{l}\text { Model 1: adjusted for age and } \\
\text { ethnicity }\end{array}$ & $3.01 * * *(1.91$ to 4.91$)$ & \\
\hline $\begin{array}{l}\text { Model 2: systemic conditions + } \\
\text { model } 1\end{array}$ & $3.06^{* * *}(1.88$ to 4.99$)$ & $-2.5 \dagger$ \\
\hline $\begin{array}{l}\text { Model 3: socioeconomic factors + } \\
\text { model } 1\end{array}$ & $2.26^{* *}(1.40$ to 3.66$)$ & 37.3 \\
\hline $\begin{array}{l}\text { Model 4: behavioural factors + } \\
\text { model } 1\end{array}$ & $2.49 * * *$ (1.54 to 4.03$)$ & 25.9 \\
\hline Model 5: models $3+4$ & $2.12^{* *}(1.30$ to 3.45$)$ & 44.3 \\
\hline Model 6: models $2+3+4$ & $2.15^{* *}(1.30$ to 3.55$)$ & 42.8 \\
\hline \multicolumn{3}{|c|}{$\begin{array}{l}\text { Model 2: systemic conditions (cardiac diseases, diabetes, hypertension, cholesterol } \\
\text { and HDL cholesterol). Model } 3 \text { : socioeconomic factors (family income, military rank, } \\
\text { education and IQ). Model } 4 \text { : behavioural factors (years of smoking, alcohol units } \\
\text { per day, treatment for alcohol or drug abuse and body mass index). } \\
{ }^{* *} p<0.01 ;{ }^{* * *} p<0.001 \text {. } \\
\text { †Adjusting for systemic conditions demonstrated an increase in death hazard for } \\
\text { edentulous persons. }\end{array}$} \\
\hline
\end{tabular}

play a role in the association between oral health and some cause-specific mortality, such as cardiovascular disease, cancerand respiratory-related mortality, they do not completely explain the persistent and strong association between oral health and mortality rates that have been repeatedly demonstrated. More importantly, the suggested inflammatory and nutrients pathways do not explain the relationship between oral health and all-cause mortality, especially when a large percentage of mortality rates are injury/accidents-related and self-inflicted. On the other hand, poor oral health could be an early marker of lifestyle and risk-taking behaviours deemed detrimental to health and survival. ${ }^{20}$ The common effect of socioeconomic position on oral health and on general health, mortality and health-related behaviours, is another plausible explanation for the association between oral health and all-cause mortality. ${ }^{25}$ Intelligence as a marker of personality traits, and socioeconomic position, is other possible factor that could explain part of the association between oral health and mortality, as they have similar relationships with each of them. ${ }^{23} 24$ The analysis of the current study confirms that this theory as the association between oral health and external cause of mortality was completely explained away after adjusting for behavioural and socioeconomic factors. An interesting observation in this study is that $3 \%$ of Vietnam War-era veterans were edentate at a relatively early age. Unsurprisingly, the edentate were at higher risk of mortality from hear- related disease and all-cause mortality.

This study demonstrated that socioeconomic factors and some common health-compromising behaviours such as smoking, drinking, drug abuse and obesity explained approximately $50 \%$ of all-cause mortality risk attributed to oral health. Furthermore, the aforementioned socioeconomic and behavioural factors appeared to play a far more important role in the relationship between oral health and mortality than chronic health conditions and biological risk factors for cardiac disease. These findings support, to some extent, the theory proposed here that oral health status is a marker of socioeconomic position, lifestyle and risk-taking behaviours hazardous to survival. The significance of our findings is that they highlight the importance of oral health as an early marker of risk factors for premature death. That marker could be complemented by behavioural and social factors, such as social relationship, unemployment, housing conditions, as they could explain most of the remaining association between oral health status and allcause mortality.

This study examined the risks for cause-specific and all-cause mortality at midlife attributed to oral health, an overall assessment of the condition of the mouth and the teeth, and a more objective measure indicating being completely edentulous. The study has the advantage of quantifying the impact of socioeconomic factors, behaviours and chronic health conditions on the relationship between oral health and all-cause mortality risk. However, the study does have some limitations. First, oral health was assessed by physicians rather than by dentists. However, others have suggested that physicians can accurately assess oral health. ${ }^{33-36}$ Furthermore, the use of a dichotomous variable indicating being completely edentulous provides a more objective measure of oral health. The study included only male veterans from the Vietnam War-era. Hence, the results cannot be generalised to the whole population. However, the findings should be of significance to the Department of Veterans Affairs. The analysis adjusted for a number of early life and midlife indicators of socioeconomic positions, behavioural factors and chronic conditions at a mean age of 38 years. Other social, behavioural, biological and health-services-related factors were not included in the analysis, which could have affected the results. However, the selection of covariates was deemed appropriate for the study objectives as they include common socioeconomic determinants of general and oral health and reflect lifestyle and health-compromising behaviours that might have a greater impact on all-cause mortality than disease-specific risk factors. For example, excessive drinking is a risk for cancer but is also linked to injury and accidents.

In conclusion, the present study demonstrated that veterans with poorer oral health status had higher all-cause mortality risks in a large sample of Vietnam War-era veterans. Indicators of socioeconomic position at early adulthood, and midlife, IQ at early adulthood, and selected health-related behaviours explained approximately $50 \%$ of mortality risk attributed to oral health and appeared to be more important than chronic health conditions and cardiovascular biological risk factors. The findings of this study suggest that health-compromising behaviours related to oral health and oral health status are early markers of life-threatening hazards.

\section{What is already known on this subject}

Oral health is associated with cause-specific and all-cause mortality. The association is attributed to inflammatory and nutritional pathways. 


\section{What this study adds}

Oral health is associated with all-cause mortality at middle age. The association between oral health and all-cause mortality is mostly attributed to the confounding effect of socioeconomic position and health-compromising behaviours. Poor oral health appears to be a marker of risk factors related to all-cause mortality.

Contributors All the authors jointly conceived the study, read and approved the final version of the manuscript. WS designed the study, analysed the data and drafted the manuscript. LHM advised on data analysis, commented on and revised the method. AS contributed to the study design, commented on and contributed to the manuscript. DB contributed to the study design, commented on and contributed to the manuscript.

\section{Competing interests None.}

Provenance and peer review Not commissioned; externally peer reviewed.

\section{REFERENCES}

1 Jansson L, Lavstedt S, Frithiof L. Relationship between oral health and mortality rate. J Clin Periodontol 2002;29:1029-34.

2 Abnet CC, Qiao YL, Dawsey SM, et al. Tooth loss is associated with increased risk of total death and death from upper gastrointestinal cancer, heart disease, and stroke in a Chinese population-based cohort. Int J Epidemiol 2005;34:467-74.

3 Heitmann BL, Gamborg M. Remaining teeth, cardiovascular morbidity and death among adult Danes. Prev Med 2008;47:156-60.

4 Awano S, Ansai T, Takata Y, et al. Oral health and mortality risk from pneumonia in the elderly. J Dent Res 2008;87:334-9.

5 Ide R, Mizoue T, Fujino Y, et al. Oral symptoms predict mortality: a prospective study in Japan. J Dent Res 2008;87:485-9.

6 Holmlund A, Holm G, Lind L. Number of teeth as a predictor of cardiovascular mortality in a cohort of 7,674 subjects followed for 12 years. J Periodontol 2010;81:870-6.

7 Aida J, Kondo K, Yamamoto T, et al. Oral health and cancer, cardiovascular, and respiratory mortality of Japanese. J Dent Res 2011;90:1129-35.

8 Garcia RI, Krall EA, Vokonas PS. Periodontal disease and mortality from all causes in the VA Dental Longitudinal Study. Ann Periodontol 1998;3:339-49.

9 Söder $B$, Jin LJ, Klinge $B$, et al. Periodontitis and premature death. A 16-year longitudinal study in a Swedish urban population. J Periodont Res 2007;42: 361-6.

10 Avlund K, Schultz-Larsen K, Krustrup U, et al. Effect of inflammation in the periodontium in early old age on mortality at 21-yearfollow-up. J Am Geriatr Soc 2009;57:1206-12.

11 Li Q, Chalmers J, Czernichow S, et al; ADVANCE Collaborative group. Oral disease and subsequent cardiovascular disease in people with type 2 diabetes: a prospective cohort study based on the Action in Diabetes and Vascular Disease: Preterax and Diamicron Modified-Release Controlled Evaluation (ADVANCE) trial. Diabetologia 2010;53:2320-7.

12 Stolzenberg-Solomon RZ, Dodd KW, Blaser MJ, et al. Tooth loss, pancreatic cancer and Helicobacter pylori. Am J Clin Nutr 2003;78:176-81.

13 Tu YK, Galobardes B, Smith GD, et al. Associations between tooth loss and mortality patterns in the Glasgow Alumni Cohort. Heart 2007;93:1098-103.

14 Fukai $\mathrm{K}$, Takiguchi T, Ando Y, et al. Functional tooth number and 15-year mortality in a cohort of community-residing older people. Geriatr Gerontol Int 2007;7: 341-7.

15 Brown DW. Complete edentulism prior to the age of 65 years is associated with all-cause mortality. J Public Health Dent 2009;69:260-6.
16 Bahekar AA, Singh S, Saha S, et al. The prevalence and incidence of coronary heart disease is significantly increased in periodontitis: a meta-analysis. Am Heart $J$ 2007:154:830-7.

17 de Andrade FB, de França Caldas A Jr, Kitoko PM. Relationship between oral health, nutrient intake and nutritional status in a sample of Brazilian elderly people. Gerodontology 2009;26:40-5.

18 Semba RD, Blaum CS, Bartali B, et al. Denture use, malnutrition, frailty, and mortality among older women living in the community. J Nutr Health Aging 2006; 10:161-7

19 Kim MK, Ko MJ, Han JT. Alcohol consumption and mortality from all-cause and cancers among 1.34 million Koreans: the results from the Korea national health insurance corporation's health examinee cohort in 2000. Cancer Causes Contro 2010;21:2295-302.

20 Kvaavik E, Batty GD, Ursin G, et al. Influence of individual and combined health behaviors on total and cause-specific mortality in men and women: the United Kingdom health and lifestyle survey. Arch Intern Med 2010;170:711-18.

21 Ford ES, Zhao G, Tsai J, et al. Low-risk lifestyle behaviors and all-cause mortality: findings from the National Health and Nutrition Examination Survey III Mortality Study. Am J Public Health 2011;101:1922-9.

22 Paganini-Hill A, White SC, Atchison KA. Dental health behaviors, dentition, and mortality in the elderly: the leisure world cohort study. J Aging Res 2011;2011:156061.

23 Batty GD, Deary IJ, Gottfredson LS. Premorbid (early life) IQ and later mortality risk: systematic review. Ann Epidemiol 2007;17:278-88.

24 Sabbah W, Sheiham A. The relationship between cognitive ability and dental status in a national sample of USA adults. Intelligence 2010;38:605-10.

25 Cabrera C, Hakeberg M, Ahlqwist $M$, et al. Can the relation between tooth loss and chronic disease be explained by socio-economic status? A 24-year follow-up from the population study of women in Gothenburg, Sweden. Eur J Epidemiol 2005;20:229-36.

26 Centers for Disease Control and Prevention (CDC). Vietnam Experience Study. http:/l www.cdc.gov/nceh/veterans/default1c.htmlast (accessed 14 Nov 2011).

27 Centers for Disease Control (CDC). Vietnam Experience Study. Health status of Vietnam veterans. I. Psychosocial characteristics. JAMA 1988;259:2701-7.

28 Centers for Disease Control (CDC). Vietnam Experience Study. Health status of Vietnam veterans. II. Physical Health. JAMA 1988;259:2708-14.

29 Phillips AC, Carroll D, Gale CR, et al. Lymphocyte cell counts in middle age are positively associated with subsequent all-cause and cardiovascular mortality. QJM 2011;104:319-24.

30 Phillips AC, Carroll D, Gale CR, et al. Cortisol, DHEA sulphate, their ratio, and all-cause and cause-specific mortality in the Vietnam Experience Study. Eur J Endocrinol 2010;163:285-92.

31 Batty GD, Shipley MJ, Mortensen LH, et al. IQ in late adolescence/early adulthood, risk factors in middle age and later all-cause mortality in men: the Vietnam Experience Study. J Epidemio/ Community Health 2008;62:522-31.

32 Gale CR, Deary IJ, Fowkes FG, et al. Intelligence in early adulthood and subclinical atherosclerosis in middle-aged men: the Vietnam Experience Study. J Epidemiol Community Health 2012;66:e13.

33 Jones TV, Siegel MJ, Schneider JR. Recognition and management of oral health problems in older adults by physicians: a pilot study. J Am Board Fam Pract 1998;11:474-7.

34 Dolan TA, Atchison K, Huynh TN. Access to dental care among older adults in the United States. J Dent Educ 2005;69:961-74.

35 Gordon SR, Jahnigen DW. Oral assessment of the dentulous elderly patient. J Am Geriatr Soc 1986;34:276-81.

36 Pierce KM, Rozier RG, Vann WF Jr. Accuracy of pediatric primary care providers' screening and referral for early childhood caries. Pediatrics 2002;109:E82-2.

37 dela Cruz GG, Rozier RG, Slade G. Dental screening and referral of young children by pediatric primary care providers. Pediatrics 2004;114:e642-52.

38 World Health Organisation. International Statistical Classification of Diseases and Related Health Problems. Geneva: WHO, 1992.

39 Lange T, Hansen JV. Direct and indirect effects in a survival context. Epidemiology 2011;22:575-81.

40 Singh-Manoux A, Martikainen P, Ferrie J, et al. What does self rated health measure? Results from the British Whitehall II and French Gazel cohort studies. J Epidemiol Community health 2006;60:364-72. 


\section{Corrections}

Sabbah W, Mortensen LH, Sheiham A, et al. Oral health as a risk factor for mortality in middle-aged men: the role of socioeconomic position and health behaviours. J Epidemiol Community Health 2013;67:392-7. The fourth author's name was published incorrectly as David Batty. The correct name should be GD Batty.

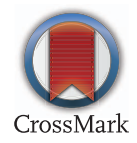

J Epidemiol Community Health 2014;68:191. doi:10.1136/jech-2012-201340corr1 